\title{
DOS MOMENTOS, DOS AUTORES EN LA HISTORIA DE UNA LITERATURA
}

\author{
María Amoretti Hurtado
}

\begin{abstract}
RESUMEN
Una cierta forma de relación entre Historia y Literatura que no permanece idéntica en el margen de una centuria (la primera de una literatura nacional) es el propósito inicial de este artículo. Su meta final es la de proyectar, gracias al examen de la obra de dos autores, una fantasía histórica, literaria y social cuyo protagonista es el sujeto nacional.
\end{abstract}

\begin{abstract}
The initial purpose of this article is to focus the radical change that has occurred in the relationship between History and Literature during the first century of National Literature. By the means of examing the work of two authors this essay dares to project a historical, literary and social fantasy whose protagonist is the national subject.
\end{abstract}

\section{La literatura como Historia y la historia como fabulación}

Cien años después de la construcción del Estado-Nación se procede a su desmitificación en parte por la crisis del modelo económico burgués y en parte también por el profundo cambio de paradigmas epistemológicos que culminan al final de esta centuria.

Entre las disciplinas más radicalmente afectadas por ese cambio de paradigmas figura la Historia, quien habiendo contribuido a construir la credibilidad del mito de la Nación, se esfuerza ahora en la tarea de desmitificarla y de demoler cualquier idealización de la cultura, limitándose a ofrecer simplemente un cuadro comprensivo de esta.

La literatura tampoco ha quedado incólume y más bien podríamos decir que ha operado como agente de ese cambio en el que el lenguaje y la imaginación son la sustancia misma del pensamiento. Por eso, la crítica literaria ha sido una de las vanguardias en la configuración de esos nuevos paradigmas epistemológicos y hay quienes incluso la señalan como pionera en la construcción de la actual cultura cibernética, especialmente cuando se piensa en la importancia fundamental que en ese campo adquiere la noción de red y la ampliación del concepto de texto y su descentramiento (Landow 1995).

Tal vez el autor que declare con mayor desenfado la actual posición de liderato que tiene la literatura en medio de las ciencias sociales, sea Richard Rorty (Clayton 1993). Este célebre pensador ha proclamado la literatura como aquella disciplina que preside actualmente nuestra cultura. El nuevo papel de la literatura se debe, específicamente, al cambio de los paradigmas interpretativos, en el que tanto la filosofía como la teoría literaria han hecho las mejores contribuciones. Así, los procedimientos interpretativos característicos de la crítica literaria se 
utilizan ahora no solamente en Ciencias Políticas o Sociología, sino también en Historia, Filosofía, Psicoanálisis, Teología o Derecho, constituyendo con este fenómeno una verdadera zona de convergencia en las Ciencias Sociales. Para no ir muy lejos, es muy señalado el hecho del aumento tan significativo de nuestra población en el posgrado de literatura justamente por estudiantes provenientes de esas áreas.

Lo social se concibe ahora como un espacio semiótico que se organiza según esquemas secuenciales que construyen narrativas forjadoras de sentido (Apter 1984). Por eso ahora los historiadores nos hablan de las "narrativas", entendiendo por ellas formas culturales preeminentes a través de las cuales se capta la arquitectura política y social de las comunidades. La narrativa, anteriormente una forma literaria, se ha convertido hoy en una categoría analítica y una herramienta intelectual (Clayton 1993 :11) .

Ahora, el papel del lenguaje, la comunicación, la problemática de la representación no son temas exclusivos de la teoría y la crítica literaria, sino que se han constituido también en temas de reflexión y debate, temas igualmente propios de la cuestión de la historicidad; pero obviamente que en esas problemáticas es la literatura y la literaturología quienes ofrecen el modelo de comprensión hermenéutica por excelencia.

Pero no sería justo, por otra parte, omitir el papel de Foucault en esta revolución de los paradigmas y, más concretamente, en esta revolución de la historia. Foucault es uno de los principales responsables de este profundo cambio de dirección del pensamiento en el siglo XX. Su crítica a una cierta racionalidad y a una cierta forma de historicidad han inducido el panorama actual. Pero hay que destacar que el famoso método discursivo de Foucault deriva de su inquietud por el lenguaje, de lo que él llama el ser del lenguaje y su relación con el saber y con el poder. Para Foucault, el ser del lenguaje se encuentra en la delgada superficie que se da entre las palabras y las cosas. Así lo explica Carlos Rojas Osorio, cuya interpretación y síntesis de una de las ideas medulares del libro de Foucault titulado Las palabras y las cosas (1966), me parece una de las más claras que he leído, por eso lo transcribo generosamente:

\footnotetext{
No se trata, pues, de un correlato real, ni de un referente, sino de un referencial que es un objeto formado por las reglas del discurso (...) Para Foucault, el ser del lenguaje no consiste en transparentar una realidad, en proyectarse sobre ella. El lenguaje no representa la realidad. ¿En qué consiste, pues, el ser del lenguaje? En el Renacimiento el lenguaje anudaba su ser con las cosas. En la época clásica el lenguaje se separa de las cosas, pero al separarse de ellas pasa al universo de la representación, en el ser interior de la representación que es el pensamiento. La representación permite a su vez un juego ilimitado de representaciones: la representación y la representación de la representación, y así en un doblaje ilimitado. Análogo al análisis de "las Meninas" en donde el pintor mismo aparece representado en la pintura, que también es representación. Análogo al Quijote donde el personaje aparece representado en la segunda parte de la obra y habiendo leído la primera parte. Pues bien, este juego de representaciones que el lenguaje permite constituye para Foucault el ser mismo del lenguaje. (Rojas 1995: 117-8).
}

Y son los poetas, según Foucault, quienes recobran el ser puro del lenguaje; de ahí que las relaciones del filósofo francés con la literatura sean entonces inevitables; valga destacar las más significativas: Jorge Luis Borges y Raymond Roussel. Esta relación es tan profunda que J.G. Melquior denomina "litero-filosofía" a este tipo de filosofía francesa ${ }^{1}$.

La posición del lenguaje en el pensamiento de Foucault se puede valorar, además, en la siguiente explicación de Paul Veyne: 
La palabra discurso nos viene con la misma inmediatez para designar lo que se dice que la palabra práctica para designar lo que se hace. Foucault no revela ningún discurso misterioso, distinto del que todos oímos, solo nos invita a observar exactamente lo que se dice. Y esa observación demuestra que en el ámbito de lo que se dice hay prejuicios, resistencias, salientes y entrantes inesperados, de los que los hablantes no son conscientes en absoluto. Dicho de otra forma, hay bajo el discurso consciente una gramática, determinada por las prácticas y las gramáticas vecinas, que revela una observación atenta del discurso (Veyne 1984: 210-1).

En Las palabras y las cosas (1966), Foucault afirma que fue Nietzsche —un filólogo- quien abrió para la filosofía esta posibilidad de pensar desde el lenguaje, posibilidad que ya se veía también en John L. Austin y su filosofía analítica.

En La arqueología del saber (1972), Foucault despliega el más completo desarrollo teórico del discurso como instrumento de análisis. Con esa metodología realiza una serie de ejercicios historiográficos que van a cambiar, a pesar de los lamentos de algunos historiadores como Bryan D. Palmer (Palmer 1990), las formas de recuperación del pasado. Los dos métodos que crea Foucault, la arqueología y la genealogía, son dos métodos históricos y ellos van a transformar la ciencia histórica.

Si existiese alguna relación entre este filósofo del siglo XX y el posmodernismo, sería precisamente este cuestionamiento de la historia o del historicismo. Es, en mucho, por la obra de Foucault que nos enfrentamos ahora a un discurso histórico menos solemne y más atento a escuchar el "rumor social"2, como también a una literatura que no tiene ningún complejo en reclamar su función y su vocación historiográfica.

La más reciente novelística española, por ejemplo, se elabora como memoria y como nostalgia asertiva ${ }^{3}$. E igualmente en Hispanoamérica proliferan las ficciones históricas, los testimonios y las historias ficcionalizadas. Olvido, memoria y nostalgia parecen ser las marcas más definitorias del momento.

Frente a los que se quejan de la poca relevancia de la literatura como forma de poder en la vida contemporánea, estas precisiones parecen presentar un panorama diferente. Si comparamos la función que parece tener actualmente la literatura dentro de la producción cultural como un todo, con el papel que jugó en la centuria anterior, tendríamos que hacer un balance positivo en favor de su significado actual. En aquella época, la preeminencia parece haber estado del lado de la historia.

\section{El cronotopo costumbrista}

Mientras en el final de la centuria anterior la literatura pretendía escribir la historia y el autor costumbrista se asumía a sí mismo y a su ejercicio como historiador de su tiempo, el historiador de este otro final de siglo se reconoce a sí mismo y a su oficio como otro constructor más de relatos, como un hacedor más de narrativas sociales.

Mientras el escritor costumbrista se armaba de los protocolos propios de la historia para aparentar que no fabulaba, el historiador de nuevo cuño se preocupa de aderezar sabrosamente su relato con detalles triviales de la vida cotidiana y títulos sugerentes que amortigüen el carácter adusto de la memoria científica ${ }^{4}$. Para aquella literatura de final del siglo XIX la historia era el modelo. Para esta historia en el umbral del siglo XXI, la literatura es el modelo. 
Por eso en aquella literatura todo lo que se contaba era "histórico" y de ahí que se contara aquello que había sido vivido por el autor, sabido por la "vox populi" o conocido por los documentos. Es decir, que el texto debía validarse por un procedimiento de objetivación, y para ello se recurría a los expedientes positivistas o se aludía a las leyes generales de verificación características de la ciencia.

Es también como consecuencia del modelo histórico que el relato costumbrista provoca la confusión terminológica entre narrador y autor transfiriendo en el mismo acto la autoridad ficcional del narrador al autor; por esa misma razón, la autoridad ficcional tiene como condición necesaria precisamente el respeto a un protocolo, especie de verosímil pragmático, logrado gracias a la estrategia de construir un mismo contexto perceptual haciendo coincidir la presencia del locutor y del interlocutor y fingir entre ellos la existencia de un consabido y de un acuerdo preinstalado.

Hoy la Historia se lanza tras la captura de lo vivido más que del acontecimiento en sí y exalta por ello lo subjetivo. Hay por eso una preferencia por otras formas de memoria: las colectivas, las personales o familiares, las culturales. Cuando de estas memorias se trata, toda pregunta o cuestionamiento sobre la posibilidad o legitimidad del relato resulta no pertinente, y los protocolos pragmáticos verosimilizantes se vuelven obsoletos porque resultan ociosos.

Mientras que en aquel entonces la literatura, en su asocio con la historia, se implicaba en un movimiento de formación de los estados y de los nacionalismos interpelando con sus ficciones a los individuos en sujetos; la literatura de nuestros días, y la historia en asocio con ella, intenta denonadadamente remontar la cadena de las transformaciones sufridas en el proceso de subjetivización, para lograr una especie de despersonalización, una especie de recuperación de la libertad y de la autenticidad. Todo ello, en un mar de confusiones entre la dinámica globalizadora de las economías, la defensa de las heterogeneidades y la posibilidad efectiva de ser lo que uno es .

\section{Dos momentos, dos autores y la historia de una literatura}

Tal vez si trazáramos una recta imaginaria entre dos puntos, podríamos visualizar mejor la evolución de la literatura costarricense en estos cien años. Al final del siglo XIX los relatos de Magón ponían en escena la ignorancia del campesino frente al ciudadano ilustrado; el habitante de "esos campos de Dios" frente al habitante de la todavía naciente ciudad. Al final de este siglo XX ese campesino o, para ser más exactos, un autor que se define como "polo"5 le da la pluma al campesino para que este inicie la revancha literaria munido ahora de lo que un proceso completo de escolaridad haya podido dejarle. Por eso, si elegimos dos puntos extremos entre esos cien años de literatura nacional, yo los seleccionaría entre el Magón de las postrimerías del siglo XIX, y el V.A. Mora en el final de esta centuria6.

Algunos aspectos sirven de común denominador entre estos autores: ambos escriben en el exilio, desde Nueva York, escriben con nostalgia y, aunque los propósitos sean muy diferentes, sus obras son de marcada tonalidad irónica.

La ironía ha sido uno de los rasgos con que muchos estudiosos han tratado de caracterizar a la literatura hispanoamericana y le han otorgado a ese tono una función didáctica o moralizante que no siempre tiene: 
Gran parte de la producción crítica y contestataria posee un sentido irónico general, y a menudo, produce la risa e induce a la reflexión, con el propósito de llevar a una toma de conciencia de la realidad (Pérez 1983 : 156).

En este sentido Quesada ${ }^{7}$ tiene razón al no ver en el caso del costumbrismo magoniano una didáctica del cambio positivo; pero en el gesticulamiento textual que efectúa la intencionalidad de la voluntad autorial se va imprimiendo la forma de una sustancia ética cuya develación sí llama a la reflexión. En otras palabras, es en la configuración de su textualidad que se ponen en evidencia las estrategias de un cierto juego de poder del que no se libran ni el campesino ni el autor-narrador. Este poder autoengendrado, que no es poseído sino ejercido, proviene de una red de disciplinas (tanto en el sentido de castigo como en el de dominios de saber) que organizan el conocimiento que dirige nuestras vidas, las vidas de todos. Las jerarquías por las que se inclinan los cuentos y cuadros de Magón no son las únicas sedes del poder, ya que este es, como dice Foucault, una microfísica de la que no escapa nadie, ni el humilde ni el poderoso.

Atrapados en esa red disciplinaria que le da forma al modo en que pensamos, el género mismo como categoría sociohistórica gobierna mucho de lo que Magón escribe. El género es entonces también una forma de poder que sujeta al escritor. Así, el costumbrismo impone una cierta episteme que implica restricciones selectivas, tal es el caso de la confrontación campo/ciudad, la cual se deriva al mismo tiempo del enfrentamiento entre civilización o cultura y barbarie o naturaleza y de la cual se deriva también el blanco criticado o aquello de lo que va a predicarse: el campesino. A partir de las conclusiones a que nos llevó un exhaustivo estudio de Magón ${ }^{8}$, podríamos afirmar que, en síntesis, el género costumbrista implica entre otras regulaciones las siguientes:

1. Una teleología: la construcción de la fantasía simbólica del Estado-Nación.

2. Ciertos conceptos: costumbres, tipicidad, localismo, comunidad, identidad, nacionalidad.

3. Criterios de aceptabilidad: legitimación histórica, objetividad y veracidad.

4. Una modalidad discursiva: todas las formas irónicas (sátira, parodia) para efectuar la crítica burlesca.

5. Una jerarquía de las prácticas sociodiscursivas entrelazadas: juridicidad (criterios de verdad), la educación (ciencia, saber), el derecho (legitimidad del orden), etc.

Esas prácticas se articulan dentro de una formación social específica (la burguesa), una formación ideológica correlativa (el modo liberal) y una formación discursiva particular (los diversos saberes disciplinarios convocados; es decir, el humanismo, ya que según Foucault la fuente genealógica de las ciencias humanas es precisamente la práctica disciplinaria) y a ellas corresponde una visión del poder, lo mismo que una técnica de subjetivación correspondiente. Desde el punto de vista republicano, el poder está en el consenso y de ahí que los textos de Magón se esfuercen por conseguirlo o fingirlo, aunque sea a base de la manipulación empática o imponiendo retóricamente una identidad del tipo "¿quién no sabe...?", "¿quién no conoce...?". Si saber, conocimiento o verdad son los hilos básicos de la red de poder en la sociedad positivo-liberal, el campesino no tiene cabida en ella más que marginalmente; así, erigir al campesino como emblema de lo nacional responde a la mera necesidad de convocar al pueblo para que este se sintiera interpelado por la Nación. 
Por eso, en el caso de la literatura de Magón, el sentido irónico es, más que una intención contestataria, una forma de construir una alianza estratégica con el lector y es, a la vez, un mecanismo compensatorio en un proceso de identificación conflictivo con lo nacional. Solo cuando se capta la ironía magoniana desde este ángulo, se puede entender la contradicción que se da entre la defensa de una literatura nacional de parte del autor y la práctica de una literatura devaluante del emblema nacional por antonomasia: el campesino. Por otro lado, la ironía en Magón no puede considerarse didáctica o moralizante, porque no sirve para corregir los vicios de su sociedad, sino para exaltarlos como actos de inteligencia; de ahí que el autor confiese, las más de las veces, su complicidad con los vicios que denuncia; como en el caso de muchos de sus relatos, por ejemplo: "Un discurso imperecedero" o "El principio de autoridad", en los que se destaca un aire de superioridad o de jactancia al jugar con la ignorancia de los campesinos, tal y como lo vimos en "El clis de sol"9.

Si en muchos casos la ironía ha jugado un papel contestatario en la literatura, ese no es el caso de Magón; por el contrario, sus textos se encaminan más bien a reforzar la entropía dóxica y las representaciones hegemónicas. Su función es la de domesticar el "rumor social" dándole certidumbre, estabilidad y autoridad. Si pudiéramos condensar el sentido transversal de tres relatos de Magón que hemos analizado en ocasiones anteriores, podríamos decir que en "El clis de sol" se trata de la pregunta "¿quién es el padre de estas niñas?"; en "Un discurso imperecedero" es más bien "¿quién es el autor de este discurso?"; y en "El principio de autoridad" la pregunta sale en busca del sentido, la pregunta es : "¿qué significa...?". Pero las tres no son más que una sola pregunta: la cuestión de la paternidad, es decir, de la autoría, la autoridad y su principio. El sentido transversal, por tanto, se podría sintetizar de la siguiente manera: todos sabemos quién es el padre, es decir, el autor del sentido. Pero claro, todos lo saben pero en ninguna parte se dice, solo se lo significa en la complicidad certificada por una comunidad de saber, es decir, por la identidad que se da entre autor y lector ${ }^{10}$. El significado existe solo porque hay al menos dos que así lo aseguran. Por eso se dice que las relaciones entre los individuos son invisibles.

La ironía carnavalesca de Bajtín nada tiene que ver con la ironía magoniana a no ser que para develar el cinismo de sus propias confesiones. La ironía magoniana, por el contrario de la bajtiniana, se coloca junto al poder. Su potencialidad crítica y paródica va dirigida más bien hacia aquellos sitios en donde es posible encontrar algún tipo de debilidad jerárquica. El humor magoniano no sustituye al significado positivo (oficial), sino que viene a reforzarlo a través del significado negativo (paródico), pero al hacerlo, pone en escena los contenidos de la sustancia ética del poder, sobre la base de los cuales este efectúa sus gestos de exclusión, sus abusos y sus atropellos; es decir, su violencia. Su ironía cumple entonces una función desvalorizante y peyorativa.

En cambio en la literatura de Mora, el humor irónico sí asume su típica función educativo-moralizante y su literatura genera una especie de discurso "atravesado" en el sentido que esta palabra tiene tanto en la semántica estándar como en el uso popular costarricense, según el cual alguien es "atravesado" cuando su actitud o acciones resultan heterodoxas o peculiares, no canónicas; efectivamente, este discurso de Mora literalmente "atraviesa" el espesor de los discursos alterando con sus propias axiomáticas las funciones instituidas de estos. Inscrito en ese contexto cultural que se ha dado en llamar posmodernidad, los textos de Mora se prohíben a sí mismos aplanar lo heterogéneo y más bien lo destacan. De ahí su heteroglosia, 
la polivocidad simultánea de los diferentes registros sociales en un discurso que se esfuerza por transcribir, a través de la oralidad, los contenidos de la cultura popular.

La literatura de Mora más pareciera la revancha literaria contestaria. Es decir que mientras Magón se ríe del "concho", del "polo", desde allá arriba, en el sitio de la cultura, cien años después el "polo" le contesta riéndose de él desde el llano de su "ignorancia". La novela A flote de V. A. Mora, digo mal, de Polo Moro, es una burla despiada -tan despiada como la de Magón cien años atrás- de la "clase culta" del país. Pero tal vez más que de la clase culta, es quizá la burla de esa clase de escritores como Magón que se alienan en su cultura. La de Mora es la inversión perfecta de la ironía magoniana.

Cien años han pasado, el "polo" pudo estudiar y usa esta cultura que ha adquirido para hacer de ella misma una caricatura y devolvérsela a la "clase culta" en la cara como una farsa. Polo no deja de ser "polo" e intenta demostrar que puede jugar con las mismas armas en la lid social sin alienarse en ellas.

En Magón hay diálogo, pero no dialogía buscada, pues si bien sus enunciados parecen destinados a ser comprendidos o respondidos por el oyente, la comprensión y la respuesta se manipulan de modo que el oyente le devuelva su propia voz como un eco. De manera que la ética magoniana es monológica y su estilo es el de un diálogo basado en la separación entre las voces. Por eso, tanto en su retórica como en su diálogo, hay una victoria y una destrucción completa del oponente gracias a la manipulación liberal del conocimiento y sus resultados opresores. Aquí la única relación intersubjetiva es la que se necesita para validar un status quo.

Entretanto, en Mora, la autoridad es una función compartida con el personaje y con el lector, en una tercera dimensión que no es ni realidad ni ficción y en la que el lector está más que fuertemente comprometido, está completamente sorprendido, por la suspensión de las convenciones tanto realistas como ficcionales y se ve por ello obligado a ejercer efectivamente su libertad interpretativa. De ahí que en la literatura de Mora el otro no es asimilable; por el contrario, el yo y su otredad conviven y cohabitan en la misma conciencia narradora. El autor implícito de Mora (idem su proyecto ideológico) es esta conciencia en busca de su autenticidad y del juego intersubjetivo que esta búsqueda implica. No hay allí más verdad que la verdad del ser individual y su destino.

Buscando ese ser individual es que el autor objetiva su propia alteridad al crear a un personaje que no es otra cosa que su imagen en el espejo, pero es una imagen que le hace muecas. Polo Moro es, pues, el yo literario del autor, el cual termina emancipándose de este hasta llegar a sustituirlo totalmente. Este hecho no deja incólume al lector, antes bien, lo deconstruye, le quita todas las ataduras retóricas y lo deja libre para que se autorrealice en el ejercicio soberano de la comprensión del texto. Por eso, el lector de Mora —a diferencia del lector magoniano, que es una réplica del autor-, es un lector difícilmente categorizable. Es un lector que debe inventarse a sí mismo, pues no es sometido a ningún proceso de normalización. Así, en Mora la sustancia ética es un llamado a la libertad individual y en Magón es una imposición a adherirse al patrón social. En aquel, el proyecto narrativo se inscribe al margen y en contra del discurso autorizado, desde el registro oral, pues es una propuesta emancipadora, fantasía política libertadora. En este, el proyecto narrativo se inscribe en el centro de la lengua dominante y su registro escrito, para autorizar o legitimar sus significados y proyectarlos colectivamente, ya que la suya es una propuesta reproductora, fantasía cultural totalizadora. 
Mientras en este se trata de describir lo que somos, quiénes somos; en aquel se trata de rechazar lo que somos para imaginar y construir lo que podríamos ser. Pero en cualquiera de los dos casos se denuncia una doxa, una episteme. En Magón de modo implícito y en Mora explícitamente. La narrativa es por eso forma cognoscitiva, y lo es independientemente de la intentio auctoris; la denuncia de la episteme se logra con solo contarla, pues contándola se hace vivir la estructura dóxica del momento histórico del que emerge el texto. Todo lo cual significa que una obra se puede constituir tanto contra la ideología como a partir de ella. En cualquiera de los dos casos se contribuye a denunciarla o, al menos, a fijar sus límites, gesto suficiente para atacarla en su más fundamental debilidad: su incapacidad para reconocer sus límites reales.

En ambos, la literatura obviamente impone las mismas reglas y leyes estructurantes, su anatropía discursiva; pero si en Magón las contradicciones se dan al intentar una escritura nacionalista que más bien toma distancia del sujeto nacional, en Mora la contradicción se da al escribir para declarar su distanciamiento respecto de ese sujeto mientras que , por el contrario, su escritura lo vuelve a inscribir dentro del mismo imaginario. Solo a través del sujeto cultural y sus textos toda escritura es posible, pero la de Mora tiene una misión transgresiva y la de Magón consolidatoria. No obstante y a pesar de la diferencia que las separa, ambas misiones se buscan llevar a efecto a través del mismo recurso: la ironía, aunque en ellas este recurso cumpla funciones muy disímiles.

A la par de la ironía, se puede agregar otro rasgo permanente a través de estos cien años. Se trata de la figura del abuso. Paradójicamente, es opinión generalizada la excesiva atención que Mora presta al erotismo, hasta el extremo de polemizarse muchas veces sobre el contenido pornográfico de sus textos. Pero si entendemos por pornográfico aquella violencia ejercida a la integridad de un ser, los textos magonianos podrían llegar a serlo. Lo interdicto en Mora es, como dice Barthes , "un espacio pesadamente prohibido pero cuyo centro es aséptico" (Barthes 1970). Mientras que en Magón -glosaríamos nosotros- lo legítimo vendría a ser "un espacio perfectamente aceptable pero cuyo centro no es tan aséptico".

En ambos autores la figura del abuso es el ideosema estructurante; solo que en la obra de Magón es violencia lingüística y en Mora se textualiza como violencia sexual. La literatura da a conocer lo real con el material que le es propio y que también forma parte de lo real: los discursos. Por eso la sociedad se inscribe en el texto no como contenido, sino como discurso; de la misma forma que se distribuye la riqueza, en la sociedad se da una apropiación desigual de los discursos. Así, en el texto de Magón, la división de los hombres se da por la palabra, en la diferencia entre lengua culta o dominante y lengua vulgar o dominada. Diferencia lingüística y diferencia social son aquí la misma cosa. Si nos fijamos en las prácticas discursivas de sus textos, en sus modos de alocución y en su lógica discursiva, podemos captar el inmenso rumor social fragmentado que ahí se figuraliza independientemente de la intención de su autor. Ese inmenso rumor social dibuja la figura del engaño, la cual se predica o comenta como signo de inteligencia; aparentando antagonizar el presente liberal y conjeturando que cualquier tiempo pasado fue mejor, el texto en realidad muestra más bien una adaptación a la sustancia ética del liberalismo, aunque dice invocar los valores del pasado. Tanto en el caso de las mellizas, como en el del discurso imperecedero, o en el del significado en "El principio de autoridad", el problema es el mismo, el de la antípoda falsedad/autenticidad y la resolución diegética también es la misma: el engaño.

La episteme que buscábamos definir comienza ahora a perfilarse. La ética lingüística, es decir, nuestro comportamiento frente a los signos — nuestras relaciones de significación-, 
son relaciones de poder que tienen una forma específica: el engaño. Lo irónico en Magón es este ocultamiento para decir la verdad silenciada de la época. La verdad, el conocimiento y el poder son las condiciones del positivismo liberal. Y siendo la literatura la tecnología más refinada para construir verdades, ella presta al mundo del liberalismo su eficiente colaboración en la construcción de su verdad simbólica. O sea que individualmente se pondrá en práctica lo que colectivamente se ha demostrado: el carácter mendaz de la ideología. Esa verdad silenciada que la ética liberal camufla es el engaño como forma positiva de inteligencia, ya que el abuso es la única respuesta comportamental para sobrevivir en el mundo liberal dominado por la estafa, por la astucia del más hábil en ocultar, en aparentar. En el mundo de los negocios, de la plusvalía robada por la transacción ideológica, que es una transación semiótica no necesariamente ligada a la verdad ni a la realidad, de lo que se trata es de la especulación del significado.

La ley, y Magón es de los que la hacen, se convierte en el ejercicio actual de unas estrategias, un procedimiento por medio del cual se gestionan ilegalismos ( el cuento titulado "Las cosas claras" ilustra claramente esta aseveración). La ley no es lo que demarca limpiamente dos dominios, legalidad/ilegalidad, tal y como se ve en el comportamiento arbitrario del campesino y todos los agentes del orden en "El principio de autoridad". Lo que hace el campesino de ese cuento, como quizá también el propio Cornelio en "El clis de sol", es identificarse con esas tácticas y revertir sus efectos de poder utilizándolas para su beneficio y con apoyo del cuadro institucional o de la autoridad que lo representa, lo cual al mismo tiempo lo invulnera de una posible censura de parte de ese cuadro institucional.

Es en este nivel ético en donde se da la captación más global de la comunidad de donde surge el texto. El resto, incluida ahí la hipotética intencionalidad de la voluntad autorial, solo puede tener un carácter subsidiario respecto de este sentido que es el sentido ético sobre el que se construye el universo del texto.

Así, cien años después, la literatura pareciera hacer justicia y reivindicar, al final de este siglo, a los millones de seres que la Historia había hasta ahora silenciado. La literatura les da hoy una voz. Son las minorías étnicas o de género, por ejemplo, las grandes protagonistas del momento.

Por eso, el "self" literario que crea Mora se erige conscientemente desde la periferia para asumir gozoso la voz del margen y el júbilo de su heteroglosia, tal y como lo escuchamos en el siguiente poema autobiográfico, el segundo retrato del autor, después del desnudo que le pintó Miguel Hernández y al cual nos referimos ya en un artículo anterior publicado en esta misma revista (Amoretti 1995):

Este soy yo... un hombre lejos de la patria, adentro y a gusto en el ocaso de su vida, que cuando pensó que ya todo se acababa, ha empezado a vivir de nuevo, con nuevos bríos, sueños, esperanzas, con un corazón que late más fuerte que nunca y una imaginación más al rojo vivo que cuando tenía veinte años...

Hecho de arroz y frijoles, barro, olla de carne, besos de mujeres tímidas y mojigatas, otras feroces, hecho de tragos, de noches enteras en vela, otras casi inconsciente, de la música del trópico, la mazamorra que vendían en mi pueblo, fortalecido de tamales, arroz con leche y los queques en los 
que se gastaba mi madre largas horas laborando...

(...)

Trabajos de todas clases y una pobreza que me dejó marcado...

Mal de patria: ese soy yo.

(...)

Soy de aquí y de allá, pero sobre todo soy del campo de mi tierra, soy de Desampa, de los Mora semilla chiverre negra para servir a usted y a toda su estimable familia.

Si los marginados fueron, como en el caso de la literatura costumbrista, tan solo tipos u objetos observables, distanciados prudentemente de la instancia narradora, en la literatura de hoy son sus voces las que se alzan desde la oralidad misma que los define en todos sus relieves; tal es el caso de los textos de Mora, textos que ensayan la construcción de un "self" propio, distanciado del centro, de la autoridad y del consenso.

\section{Notas}

1. Creo que en este sentido el extremo más flagrante es Jacques Derrida.

2. Esta expresión fue acuñada en la escuela sociocrítica de Montreal por Marc Angenot y Régine Robin como una forma más de denominar el complejo sociodiscursivo al que ellos también llaman "discurso social" y que en términos generales recoge una cierta memoria de la doxa, aquello que forma e informa las mentalidades. Está constituido por opinión pública, paradigmas más construidos, saberes disciplinarios, temas en migración con sus complejos de predicados, epítetos, historiosofías o grandes doctrinas construidas como visiones del mundo, etc.

3. Recientemente se ha presentado una interesante investigación sobre este tema en la Maestría en Literatura de la Universidad de Costa Rica. Se trata de la tesis defendida por Djordje Cuvardic García titulada La desmitificación nostálgica neofabuladora de la nueva narrativa española en Beatus Ille de Antonio Muñoz Molina. Enero de 1998. En este trabajo se examina prolijamente la dialéctica temporal entre pasado y presente, dentro de esta nueva estética de la nostalgia. Allí también se clasifican y definen las principales especies nostálgicas de la narrativa contemporánea.

4. Piénsese tan solo en algunos títulos como: Héroes de moda y libros al gusto (1992). El que quiera divertirse (1995). Otros: "El paso del cometa por la cultura costarricense de 1910", "De lo devoto a lo profano", "De compras en una librería", etc.

5. La noción de "polo" recoge el sema de la marginalidad derivado de la figura del "campesino". Si "concho" remite a la falta de refinamiento y la naturaleza tosca y sin pulimento del campesino; "polo" connota más bien la inadecuación, la inadaptación. Por eso, dentro del cronotopo costumbrista el campesino es un signo que emerge tan solo para aplicarle el deleatur, pues en el paisaje de la naciente ciudad es un elemento que no calza; de ahí que en la posterior evolución de la literatura costarricense, el "polo" estará destinado, por su inadaptación a la urbe, a convertirse en el "paria" del realismo social.

6. Para una idea panorámica sobre la literatura de este autor, véase "Ese odioso de Mora". In Revista de Filología y Lingüística. XXI (2), julio-diciembre de 1995. p. 7-16.

7. Ver la caracterización que de la obra de Magón hace este crítico en Formación de la narrativa costarricense (1890-1910). San José: Editorial Universidad de Costa Rica. 1986. 
8. La investigación a que me refiero aborda, por medio del análisis de la obra de Magón, la problemática histórica del costumbrismo como género y su relación con la formación identitaria, lo mismo que el papel que desempeñó en el forjamiento del concepto de "nación". Este trabajo se ha dado a conocer fragmentariamente en diversos artículos en la Revista Káñina y posiblemente aparezcan luego publicados como libro. Esas publicaciones se han incluido en la bibliografía que aparece al final del presente artículo.

9. $\quad$ Veáse el artículo "Dos vivazos y un tonto en un certamen de mentiras". Káñina. XXII (2), 1998.

10. Sobre este tema es interesante recalcar la coincidencia teórica entre mi citada investigación sobre Magón y un trabajo publicado por Jorge Chen bajo el título de "La fuerza centrípeta y la noción de imperio en La Gramática Castellana de Nebrija" (Káñina. XVIII (1), pág 219-227, 1994). Tanto en su artículo como en el que yo publico en esa misma revista con el título de "Dos vivazos y un tonto en un certamen de mentiras" (Káñina. XXII (2), 1998.), se examinan las estrategias de creación de una nacionalidad (en el caso de España, en la aurora del naciente imperio; y en el caso de Costa Rica, en el momento de la consolidación del Estado-Nación, al final del siglo XIX). Esa identidad nacional se logra en sendos textos (el de Nebrija, por un lado y el de Magón, por otro) gracias a la utilización de ciertos recursos pragmáticos que evidencian la presencialidad del auditorio y con ella la idea de que este y el autor comparten la misma opinión; de esa forma, por medio de esta comunidad de saber o de opinión, se crea una afiliación, se conforma una alianza tácita y se institucionaliza un supuesto consenso. En el caso particular de Magón, habría que destacar el papel que desempeña la ironía para reforzar esa cooptación y el secreto de esa alianza. La ironía coacciona al auditorio a situarse del lado del autor para ponerse a distancia del objeto burlado, del otro, de modo que en el caso de Magón se trata además de una cooptación estratégica y forzada. Pero resultando que "el otro" es precisamente el campesino, el emblema del discurso nacional, la ironía sirve entonces también para develar la ambigüedad del discurso nacionalista y lo conflictivo del proceso identificatorio en Costa Rica. Tal y como ya lo afirmamos en el desarrollo de este artículo, la ironía pone entonces en evidencia un mecanismo de compensación que le permite al individuo asimilar el emblema identitario y deplorarlo implícitamente al mismo tiempo.

\section{Bibliografía}

Amoretti, María. 1995. "El odioso de Mora". Revista de Filología y Lingüística. XXI (2), julio-diciembre, 7-16.

1997. "Propuestas metodológicas para una lectura diferente de los textos de Magón. Káñina. XXI (2).

1998. "Autor y autoridad. Cuestión de principios...". Káñina. XXII (1).

1998. "Dos vivazos y un tonto en un certamen de mentiras". Káñina. XXII (2).

1999. " El discurso imperecedero de Magón". Káñina. XXIII (2).

Angenot, Marc y Régine Robin. 1991. "La inscripción del discurso social en el texto literario". Sociocríticas. Prácticas textuales. Cultura de fronteras. Editora Pierrette Malcuzynski. Amsterdam-Atlanta: Rodopi.

Apter, D. E. 1984. "The new mytho/logics and the specter of superfluos man". Social Research 52 (2): 269-307. 
Barthes, Roland. 1970. A/Z. París: Seuil.

Bourdieu, Pierre. 1988. Cosas Dichas. Buenos Aires: Gedisa.

Claiton, Jay. 1993. The pleasures of Babel. Contemporary American Literature and Theory. New York: Oxford Univesity Press. .

Foucault, Michel. 1972. La arqueología del saber. México: Siglo XXI. Trad. de Aurelio Garzón del Camino.

Foucault, Michel.1966. Les mots et les choses. París: Gallimard.

Landow, George P. 1995. Hypertext. The Convergence of Contemporary Critical Theory and Technology. Baltimore and London: The Johns Hopkins University Press.

Miranda Hevia, Gladys Alicia . 1985. Novela, discurso y sociedad (Diario de una multitud). San José: Mesén Editores.

Molina, Iván. 1995. El que quiera divertirse. San José: Editorial de la Universidad de Costa Rica.

Molina, Iván y Steve Palmer. 1992. Héroes al gusto y libros de moda. Sociedad y cambio cultural en Costa Rica (1750-1910). San José: Editorial Porvenir y Plumsock Mesoamerican Studies.

Mora, V. A. 1996. A Flote. Miami: Ediciones Universal.

Palmer, Bryan. 1990. Descent into discourse. The reification of Language and the Writing of Social History. Philadelphia: Temple University Press.

Pérez, María. 1993. "Ironía,dependencia y humor en la producción significante latinoamericana". Revista de Filología y Lingüística. IX (1): 155-66.

Quesada, Álvaro. 1986. Formación de la narrativa costarricense (1890-1910). San José: Editorial Universidad de Costa Rica.

Veyne, Paul. 1984. "Foucault revoluciona la historia". Cómo se escribe la historia. Madrid: Alianza Editorial. 199-238. 